\title{
THE NEW AQUARIUM AND NEW SEA-WATER CIRCULATION SYSTEMS AT THE PLYMOUTH LABORATORY
}

\author{
By Douglas P. Wilson, D.Sc.
}

The Plymouth Laboratory

(Plates I and II, and Text-figs. I-6)

Before describing the new aquarium some mention should be made of the final state of the old, which was described in detail some years ago (Wilson, 1952). Various suggestions for improvement made at that time were subsequently carried out. Thus the central table tanks were removed in 1953 and the central curtains, after shortening, were hung from the ceiling above the front top edge of the south-side tanks. This gave greatly improved viewing of the tank contents through exclusion of direct daylight to the public hall, and the viewing was still further improved when the south-side windows were blackened inside and the tanks lit solely by electric light. Modifications to the reservoirs (described below) brought about a clarity of the sea water never before attained.

The end came when the slate backs of several south-side tanks developed serious cracks, through which at one time water was pouring at over 70 gallons an hour and finding its way out of the building through ventilators in the south wall. No more than temporary repairs could be effected. The cracks resulted from the rusting of iron bolts pinning together the slate slabs of which the tanks were built. The bolt heads had been covered with slate dowels bedded in a red-lead compound which had kept the water back for nearly 70 years; it had at last penetrated to the bolts and expansion due to rusting cracked the slates.

The old aquarium was closed to the public for the last time on 27 September 1958 and demolition of the old tanks and fittings took most of October. It is of interest to record that the cast-iron window frames-which were moulded with the name of Leete, Edwards and Norman, London, a firm well known in Victorian days for its constructional work on big public aquariawere in excellent condition and doubtless would have served for many more years. The condition of the iron tie-bars was on the whole also good, even in places where they had never been repainted and had a thick coating of rust, though here and there they had become dangerously thin. Much of the slate was in poor condition, splitting easily where rusting iron had cracked it and it would certainly not have held out much longer. 
All the more valuable fish removed from the old tanks were, during the rebuilding, kept in tanks outside in the yard, or in the sea-water reservoirs, the water being kept in circulation. In the dimly lit reservoirs the fish flourished and grew, particularly Pagellus, Spondyliosoma and Morone. The Polyprion, mentioned in Wilson, 1953, p. 207, had a reservoir to itself and lengthened noticeably.

\section{THE NEW AQUARIUM}

Over many years various tentative plans for a new aquarium had been drawn and discarded. The necessity of erecting the new tanks within the existing tank room, where the central columns supporting the floors above must be retained, imposed severe limitations within which it was difficult to achieve a harmonious design pleasing to the viewer and at the same time providing greatly improved servicing facilities and a healthier environment for the animals. In the final plan these desiderata have largely been satisfied though at a cost of innumerable compromises. Thus, because of the restricted ceiling height the depth of water in the tanks is the maximum possible consistent with barely reasonable headroom over the cat-walks, and the latter have had to be kept several inches closer to the water surface than is desirable. Similarly the length and width of the tank room has influenced the shape of the tank windows, which are several inches shorter than they could otherwise have been. And so on throughout the whole structure.

In 1952 Garnaud suggested new shapes for aquarium tanks, until then almost always based on the rectangle. He proposed that the side walls should be built at $45^{\circ}$ angles instead of at right angles. By so doing, triangular tanks alternate with others in which, owing to refraction and reflexion of light, the side walls cannot be seen through the windows when the tanks are full of water. This idea of angled-sides was adopted for the new aquarium at Plymouth, but modified from Garnaud's original scheme to accord with requirements within the available space.

In planning the aquarium the main objectives have been: (I) provision of the best possible conditions for the animals; (2) that as seen by the viewer each tank shall present as natural looking a scene as possible, well illuminated and with no 'works' showing; (3) ease of maintenance and day-to-day servicing. The first of these objectives has always taken precedence over the other two and the second almost always over the third. Only by so doing can a healthy and attractive aquarium be attained. In addition, the public hall and its approaches have been made as well proportioned and pleasing as possible.

The architect was Mr F. L. Preston, F.R.I.B.A., A.A.Dip., of Messrs Easton and Robertson, Cusdin, Preston and Smith, London, and the con- 
tractors Messrs John Garrett and Son Ltd, of Plymouth. The rockwork was designed and executed by Mr H. R. Allen, A.R.C.A., of Westerham, Kent.

Much technical help was given by members of the laboratory staff, especially $\mathrm{Mr} \mathrm{A}$. N. Bennett in the planning of the circulation system and Mr F. J. Warren in electrical fittings. Mr F. G. W. Ryder helped with many constructional details and overall supervision.

To all the above and others from whom I received assistance during the planning and construction of the new aquarium I wish to record my grateful thanks, and also to the Director, Dr F. S. Russell, F.R.S., for his continued support and encouragement.

\section{The public hall}

In the old aquarium ${ }^{1}$ the tanks lined the north and south walls of the building and because they were wider on the north than on the south side the pillars occupied an asymmetrical position between them. By making the new north- and south-side tanks of equal width (see Text-fig. I) these pillars are now centrally placed and one, the former easternmost pillar, has been removed to enable the largest tank to be constructed at the east end of the room. The weight of the floor above has been taken by two new concrete pillars merged with the central mullions of this tank. The public hall, as will be seen from the plan, widens at the east end. The new layout has in itself greatly enhanced the general appearance of the aquarium (P1. I) and this has been further improved by an acoustically tiled ceiling with inset lights, hung below and concealing from public view the old vaulted ceiling and the unsightly overhead piping supplying tanks in the laboratory on the floor above. Underfoot a floor of dark red asphalt is a pleasing substitute for concrete with iron gratings. The public reach the aquarium along a partly reconstructed and newly decorated hall and passage and enter it through swing-doors and a small low-ceilinged lobby.

Wooden sides to the lobby, fluted and polished, are service doors which enable staff to cross it between north- and south-side service areas. These service areas, or short passages, are cut off from the public hall by a fluted polished screen of Afrormosia wood in which, to the north of the lobby, are three small angle-iron tanks, one below and two above, attractively framed in the screen (Text-fig. 2, section AB). In the south-east corner an emergency exit has been constructed utilizing one of the old window arches. A circular seat has recently been put around the pillar nearest the large tank.

On the sills in front of the tanks (Pl. I) frames of Afrormosia wood hold picture labels (lettered water-colour drawings sealed between Perspex). Each frame holds five labels which can be slid in from either end and screwed up against interference. A removable wooden hand-rail on iron supports inserted

${ }^{1}$ Photographs of the old aquarium are reproduced in Allen \& Harvey, I928 (fig. 6), Russell, 1948 (pl. XXIII), and Wilson, I952 (pl. I). 


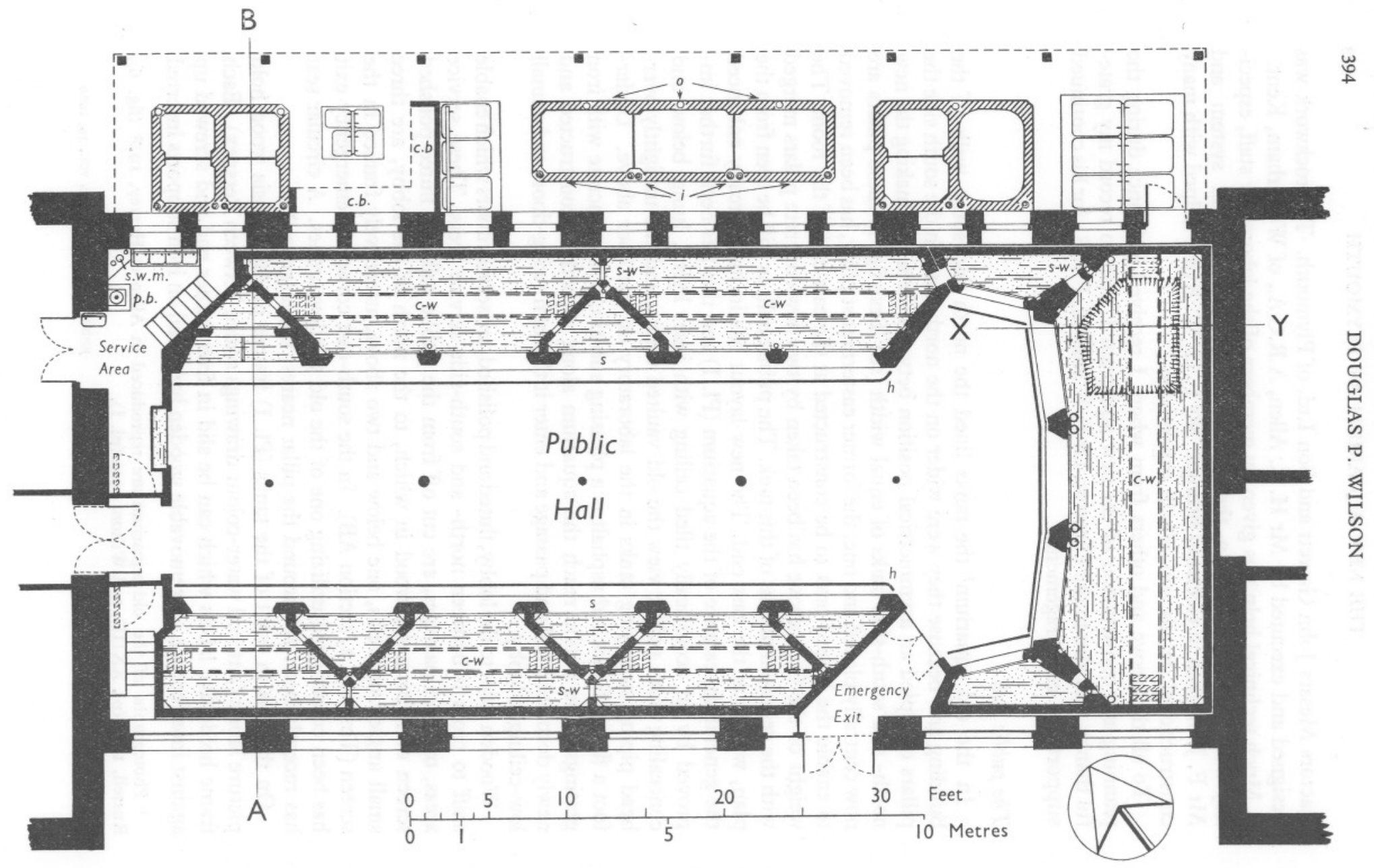

Text-fig. I. For legend see facing page. 


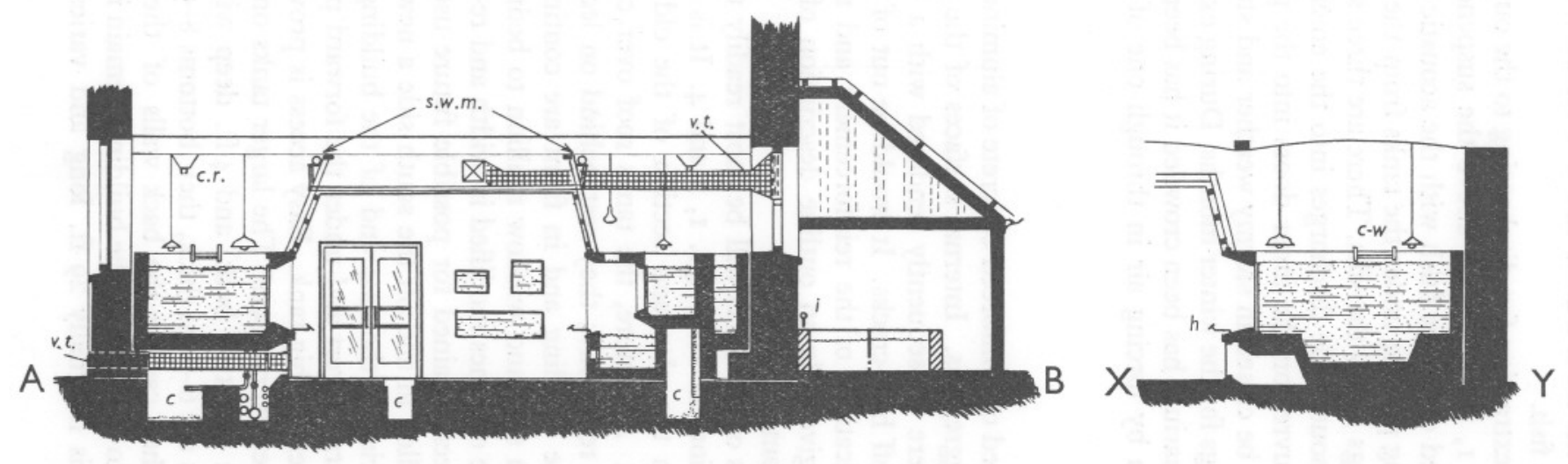

Fig. 2

Text-figs. I and 2. Plan and sections of the new aquarium and new outside circulation. Water in the exhibition tanks is 'indicated by line and dot stippling. $c$, sea-water return culvert; $c . b$., circulation bench; c.r., overhead conveyor rail (Henderson track); $c$-w, cat-walk; $h$, hand-rail; $i$, inflows; $o$, overflows; p.b., plunger bucket; $s$, sill; $s$-w, swim-ways; s.w.m., sea-water main. 
in the sill, about $3 \mathrm{ft}$. above floor level and nearly $2 \mathrm{ft}$ from the glass, gives some protection to the latter and to the label frames and is a comfortable support to lean on whilst watching the fish.

The hall is ventilated by an extraction fan discharging to the outside at the north-west corner (Text-figs. I, 2). Trunking above the suspended ceiling draws air through three louvred openings flush with the acoustic tiling. Air enters the hall through trunking passing under the tanks from the outside of the building to louvred openings below the sills. There are three such trunks on each side, but one on the south side discharges into the emergency exit passage, and then through louvres on the inner doors into the public hall. Louvres on the south side can be closed in stormy weather and storm covers are fitted on the outside openings for the winter months. During exceptionally hot calm weather when the aquarium has been crowded it has been necessary to augment normal ventilation by forcing air in through one of the intake trunks on the north side.

\section{Basic construction of the tanks}

The new tanks are constructed of reinforced concrete of aluminous cement mixed with local sands and aggregates. Internal surfaces of the back walls and parts of the side walls were subsequently rendered with a waterproof cement and sand mix to seal off hair-cracks. It would be out of place here to give full engineering specifications of the reinforcement and methods of construction; it is feasible to give only an outline description of the tanks as they can be observed in a completed state.

The arrangement and shapes of the tanks will be most readily understood by a study of the plan and sections in Text-figs. I, 2 and 4 . It is instructive to compare these figures with the plan and section of the old aquarium (Wilson, 1952, text-figs. I, 2). As before, the tanks roof over culverts returning overflow water to the reservoirs; they rest behind on ledges at the bases of the main walls of the building and in front are continuous with concrete pillars extending each stile and window mullion to bedrock below floor level. The culverts are the old ones modified in width and re-asphalted. The old central culvert has been retained for possible future use. The old drainage trenches have been filled in and on the south side a new trench to carry services to the laboratories at the east end of the building has been excavated alongside the southern culvert and under the forward parts of the tanks. These services pass under the big tank. Easy access is provided to all culverts and to the service pipes everywhere. The larger tanks on the north and south sides are $6 \mathrm{ft}$. wide (front to back) and $4 \mathrm{ft}$. deep with a water depth of $3 \mathrm{ft} .6$ in. Their walls are 6-7 in. thick, their bottoms $8-9$ in. thick. Creosoted soft-boards used when casting the back walls of the tanks, to prevent the concrete adhering to the walls of the building, remain in position. The big tank at the east end is internally $29 \mathrm{ft}$. long and varies in width 
from about $8 \mathrm{ft} .4$ in. at the centre to about $9 \mathrm{ft}$. 3 in. near each end. The bottom of this tank is about ro in. thick, and at the north end it drops down to a lower level over an area irregular in shape, thereby increasing the water depth at this place by about I ft. 3 in. The small tanks with a water depth of rather less than $2 \mathrm{ft}$. 6 in. occupy the corners between the ends of the big tank and the north- and south-side series. On the north side at the west end a shallow triangular tank overlaps a floor tank which is divisible into two with a removable partition or, as at present, by built-in rockwork. The floor tank is viewed only through the water surface and is designed for the display of flatfishes on contrasted bottom shingles. Except for this floor tank the water surface in all the tanks is at a uniform height, permitting openings to be made between tanks as described below (p. 402).

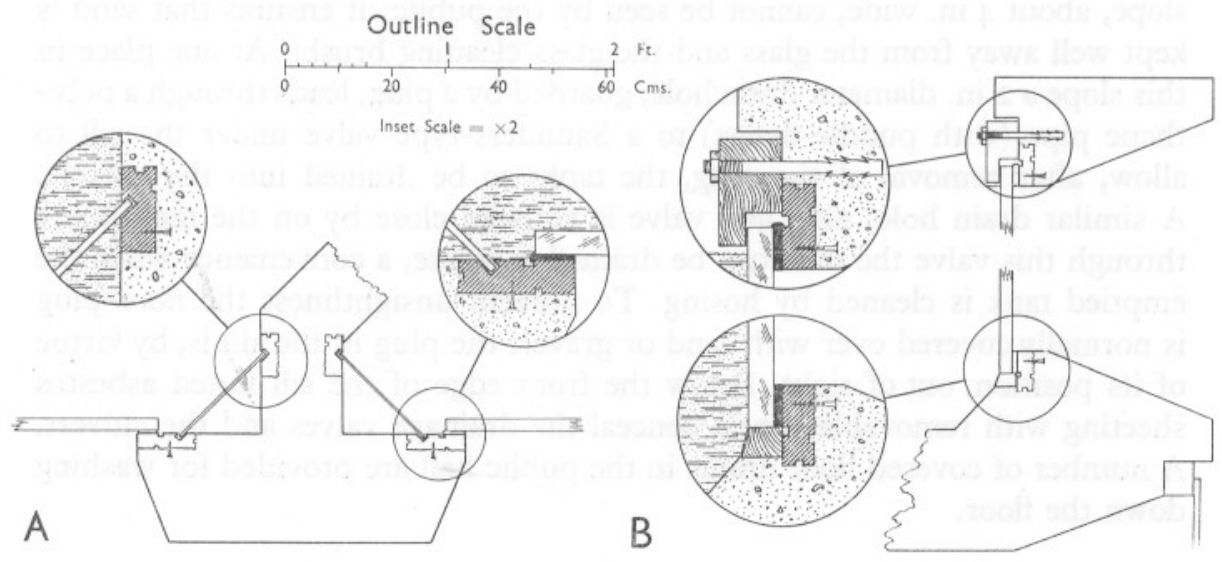

Text-fig. 3. A. Plan of a stile between a triangular tank on the right and a larger tank on the left, including a portion of the dividing wall with polythene sheets slid into slate slots to form inflow ducts. Inset are details of slotted slate inserts keyed to the concrete by grooving and rustless-steel screws. In the right inset is shown the edge of a glass pane with sealing compound ('Glasticon', drawn solid black) between it and the slate.

B. Section of a tank front showing lintel walk-way and sill. Inset above are details of teak turnbuckle on rustless-steel rag-bolt, top edge of glass, water level, etc. Inset below shows bottom edge of glass resting on teak block on ledge of sill with details of grooved slate inserts, sealing compound, etc.

Except for the shallower tanks all the window openings are of uniform size, $5 \mathrm{ft}$. $7 \frac{1}{2}$ in. long by $3 \mathrm{ft}$. high. One advantage of this uniformity is that a single spare pane of glass fits all tanks except the shallow ones. The glass panes, I in. thick, overlap the window opening $I \frac{1}{2}$ in. all round. These openings are formed of slate inserts keyed to the concrete (Text-fig. 3). The slates are grooved to give facings exactly $\mathrm{I} \frac{1}{2}$ in. wide. This is necessary to achieve uniformity of pressure on the sealing compound and to aid in positioning the glass. The glass is pressed by water pressure against the sealing compound 'Glasticon' ('Glasticord' 304) laid in strip form on the facings 
(for method of glazing see Wilson, 1952, p. 195). A single teak turnbuckle fixed to the frame above the middle top edge of each pane prevents accidental falling inwards of the glass when the tank is emptied.

The top edges of all window openings are $5 \mathrm{ft}$. 7 in. above floor level all round the aquarium. The heads or lintels are wide and flat topped, they carry the sloping sides of the suspended ceiling and form convenient walk-ways for servicing the tanks (Pl. II, fig. I), especially for glass-cleaning. The sills are also wide and carry externally the label frames and support the hand-rail already described. Within each tank the sill provides a ledge $I_{2}^{\frac{1}{2}}$ in. wide on which the bottom edge of the glass pane rests, though indirectly with two teak blocks near either end between it and the concrete (Text-fig. 3). From this ledge the sill slopes downwards at $45^{\circ}$ to the tank floor (Text-fig. 4). This slope, about 4 in. wide, cannot be seen by the public; it ensures that sand is kept well away from the glass and the glass-cleaning brush. At one place in this slope a 2 in. diameter drain hole, guarded by a plug, leads through a polythene pipe (with puddle-flange) to a Saunders-type valve under the sill to allow, after removal of the plug, the tanks to be drained into the culvert. A similar drain hole, plug and valve is situated close by on the tank floor; through this valve the tank can be drained to waste, a convenience when the emptied tank is cleaned by hosing. To prevent unsightliness the floor plug is normally covered over with sand or gravel: the plug in the sill is, by virtue of its position, out of sight. Below the front edge of the sill fluted asbestos sheeting with removable panels conceal the drainage valves and the culvert. A number of covered floor drains in the public hall are provided for washing down the floor.

\section{Circulation}

At the time of writing the same two centrifugal pumps mentioned in a previous paper (Wilson, 1952, p. 204) maintain the circulation, but new pumps of larger capacity will be installed in the near future. The old 4 in. vulcanite main rising from the engine room in the north-west corner (Textfig. I) feeds into a new 3 in. black polythene ('Alkathene') pipe which divides into two branches, each controlled by a Saunders valve, one to the northside tanks and one to the south. These two mains run close to the true ceiling above the corner of the suspended ceiling (Text-figs. 2, 4); there they are readily accessible. Cleaning eyes are provided at bends where needed. From these high-level mains down-dropping $I_{2} \frac{1}{2}$ in. pipes, also of black polythene and controlled by Saunders valves, lead through smaller branches to nozzles injecting water into the tanks (Text-figs. 4,5 and Pl. II, fig. I). In the old aquarium the mains lay along the tops of the tanks not far above water level and numerous nozzles injected water and air bubbles into the tanks. Not only were these mains an obstruction to servicing but the inflow method was inefficient, for only a portion of the water ever reached tank bottom and 


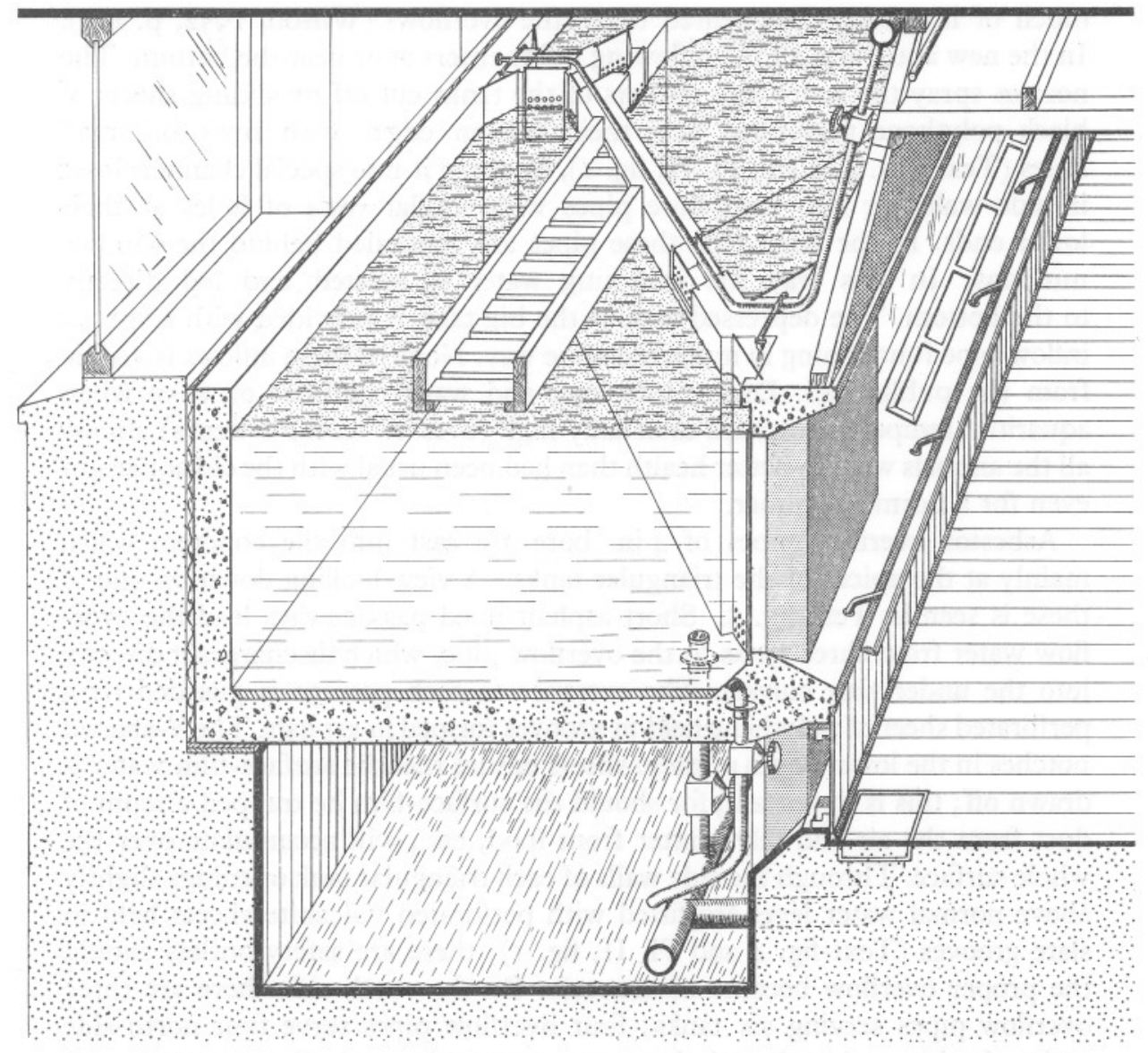

Text-fig. 4. Section through a north-side tank incorporating perspective view facing east and showing portions of three tanks and part of the public hall. Behind the tank is the main wall of the building with a window. The back of the tank rests on a footing of the wall, but indirectly on copper plates forming a sliding bearing to allow for possible movement; the plates are sealed from the sea-water circulation. Between the back wall of the tank and the wall of the building is a layer of creosoted soft-board which during construction prevented the liquid concrete from adhering to the building. Under the tank is an asphalt-lined seawater return culvert within which is a drain pipe running to waste From this drain pipe there is a connexion, through a valve, to the tank floor and through an open pipe another branch leads to a covered sump in the public hall. A drain in the tank sill, controlled by a valve, can discharge water into the culvert and so back to the reservoirs. At the apex of the triangular tank there is an overflow serving all three tanks, a swim-way between the two larger tanks, and to the latter an inflow each. These structures are shown in greater detail, viewed from above, in Text-fig. 5. A portion of a cat-walk is shown, and in the wall on the nearside a safety overflow from the triangular tank is seen. Still farther forward are two inflows, one of them to the triangular tank. The polythene branch pipe, with Saunders valve, serving the inflows, leads down from the sea-water main at ceiling level. Nearby is the main compressed-air pipe, but no valves or branch connexions to this are shown. In the public hall are seen the handrail with supports inserted in the concrete sill; label frames between it and the glass; and below the sill, fluted asbestos sheeting down to floor level. 
much of it quickly disappeared down the overflows (Wilson, 1952, p. 199). In the new aquarium all the inflowing water enters at or near the bottom. The nozzles spray the water into corners of the tanks cut off by sliding sheets of black polythene perforated near their bottom edges with rows of small holes (Text-figs. 4, 5 and Pl. II, fig. I), or spray it into special channels inset in side walls, or into large-bore pipes with similar rows of holes at their lower ends. In the large tank these pipes are concealed behind the window mullions. In this way the incoming water is aerated and led directly to the bottom. The depressed area in the big tank is provided with a special inflow pipe functioning in much the same way. None of these inflows is visible from the public hall. During the long and warm summer of 1959 when aquarium temperatures were unusually high (over $18^{\circ} \mathrm{C}$ for 6 weeks) almost all the animals were in better health than had been usual with the old aquarium even for a normal summer.

Asbestos overflow pipes of 4 in. bore are cast into the concrete walls, mainly at the apices of the triangular tanks. A view looking down on one of these is seen in Text-fig. 5. Short asphalt-lined passageways lead the overflow water from three tanks to the overflow pipe, which discharges it directly into the underlying culvert. The entrance to each passage is guarded by a perforated sheet of polythene held in grooves formed in asphalt. The V-shaped notches in the lower edges of these sheets ensure that the surface-film water is drawn off; this is important, for should the surface-film be trapped a scum of dust from the air and oily matter from food, etc., will accumulate over the whole surface. Through the side walls of each triangular tank openings slightly above normal water level are fitted with perforated vulcanite sheets held in slate grooves (Text-fig. 4 and Pl. II, fig. I); these are safety outlets should the proper overflow become obstructed. On the south side there are three overflow pipes serving six tanks; four overflow pipes serve four north-side tanks, the big end tank and the two corner tanks, and all seven tanks can overflow into one another. It is thus impossible for tanks to overfill unless all overflow pipes of a series are simultaneously blocked, which is virtually impossible.

The divisible floor-tank in the north-west corner has two large-bore overflow pipes draining away surface-film water to keep it clear.

\section{Compressed air}

In the new aquarium compressed air is used for two purposes only: (I) for lifting water from lower levels to the surface, thereby assisting in maintaining water movement within the tanks; (2) for imparting a rippled surface to bring about a play of light and shade over rocks and gravel, as occurs naturally in shallower regions of the sea.

The air is bubbled up inside pipes of 3 in. bore (concealed behind two window mullions on the north side), or in tank corners behind polythene sheets 


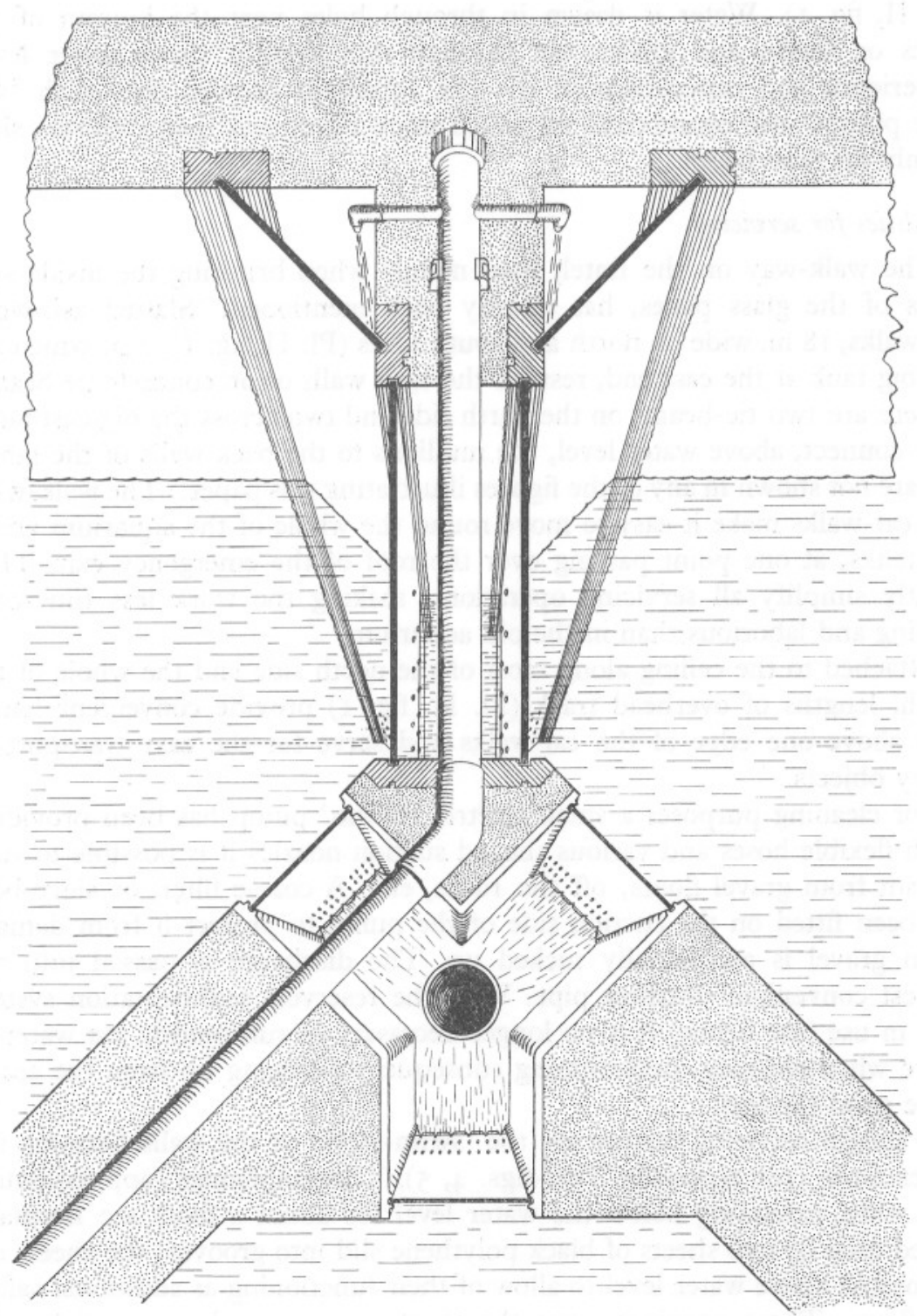

Text-fig. 5. Perspective drawing looking down on an overflow serving three tanks, a swimway between two tanks, and inflows to two tanks. The top faces of the concrete are stippled; of the slate inserts hachured; while the top edges of the sliding polythene sheets are solid black. The top edges of the asphalt lining of the overflow channels are unshaded. Water is shown by dashed lines. 
(Pl. II, fig. I). Water is drawn in through holes near the bottom of the pipes or sheets and gushes out through slits slightly above water level. Experience and experiment in the old aquarium showed that such 'airpipe pumps' use compressed air much more effectively than diffusers sited openly on tank floors.

\section{Facilities for servicing}

The walk-way on the lintel, used mainly when brushing the inside surfaces of the glass panes, has already been mentioned. Slatted ash-wood cat-walks, I8 in. wide on north and south sides (Pl. II, fig. I), $2 \mathrm{ft}$. wide over the big tank at the east end, rest on the tank walls or on concrete tie beams. (There are two tie-beams on the north side and two across the big east tank; they connect, above water level, the mullions to the back walls of the tanks, but are not shown in any of the figures illustrating this paper.) The walk-ways and cat-walks make it easy to move round the whole of the aquarium above the tanks, at one point passing over the roof of the emergency exit. They greatly simplify all servicing operations, making the work less time-consuming and laborious than in the old aquarium.

Attached to the ceiling along most of the north side and the whole of the south, lengths of overhead track (Pl. II, fig. I) provide convenient handrails above one edge of the cat-walks and serve for the easy transport of heavy objects.

For cleaning purposes a small electric 'Mono' pump has been provided. With flexible hoses and various shaped suction nozzles it is possible to suck out silt from gravel floors, off the rocks, etc. A coarse filter, or sieve-box, has been fitted on the suction side of the pump to protect it from damage when gravel is accidentally sucked up. The discharge is passed into the nearest convenient overflow pipe. With the reservoir sedimentation system now in use (see below) it is no longer necessary to run muddy sea water to waste when cleaning, necessitating subsequent pumping up from the sea to make good the loss.

A special servicing feature are the 'swim-ways' in the walls between the larger tanks (see especially Text-figs. 4, 5). These openings (approximately $\mathrm{I} \mathrm{ft}$. wide, extending below the water level for about a foot) are normally closed each by two sheets of black polythene slid into grooves; the sheets are perforated above water level to allow of their functioning as additional safety overflows. These openings, once the sheets are removed, permit fish to be swum from one tank to another as desired. Thus during a major tank-cleaning operation the fish of one tank will be netted and removed to storage tanks in the yard, choosing for netting easily caught and not readily damaged species such as dogfishes and conger eels. The swim-way adjacent having been made watertight (with a bolted-on cover and sealing compound) this tank will be emptied, cleaned and reflooded. The swim-way will then be opened and the 
fish in the next tank (species such as whiting which are easily damaged by netting) will be driven through into the cleaned tank and shut off there. Their tank in its turn will be emptied and cleaned and made ready for the reception of fish from a tank farther on. Finally, when the whole series has been emptied and cleaned one at a time, the fish will be driven back into their own tanks and the dogfishes and conger eels brought back from the yard. In this way handling of fish will be reduced to a minimum.

In the north-west service area (Text-fig. I) a number of small asbestos tanks are used to store live food (shrimps, crabs, mysids, worms, etc.) and to accommodate recently caught small animals until such time as they are placed in the exhibition tanks. This corner also houses the 'plunger-bucket' (to work 'plunger-jars' in a laboratory above) which is supplied with water from the north-side series of tanks.

\section{Lighting}

It is hardly possible to light an aquarium satisfactorily by daylight. Daylight is too variable in intensity and whatever the orientation of the tanks some will always be more brightly lit than others. When the sun shines strong reflexions of the sunny side will be seen in the darker side unless a curtain, as in the old aquarium, be hung down the middle of the public hall. Too much daylight induces rapid growth of small algae which on dying break up and produce silt; the result is dirty tanks. Back-lighting from windows behind the tanks, a standard feature of many Victorian public aquaria some of which still survive, illuminates the sides of the fish away from the viewer and leaves the backs of the tanks in semi-darkness. A few translucent objects-some sea anemones, ascidians, dogfish eggs, etc.-look well when back-lit but the majority of opaque animals do not. The tanks should be more strongly lit than the public hall, to avoid as far as possible reflexions of people in the glass and to make the tanks appear as a series of bright living pictures within their darker frames.

To exclude daylight the south-side windows have been fitted inside with asbestos sheeting. On the side facing the glass the sheeting is enamelled dark blue, purely as an architectural feature when seen from outside the building. Three windows have been left to open to obtain ventilation while admitting a minimum of daylight (Pl. II, fig. I). On the north side the windows are sufficiently screened from the sky by the roof over the new outside tanks (see below).

The public hall (P1. I) is lit mainly by light passing through the tanks aided by a series of recessed lights in the suspended ceiling. It is dim but not completely dark, there being sufficient illumination to see any object on the floor and to allow the Guide Book to be read.

Over the tanks two lines of electric conduit tubing are fixed at main ceiling level, one between the cat-walk and the glass and the other between the cat- 
walk and the backs of the tanks (Pl. II, fig. I). At selected points screwed waterproof three-pin sockets are provided from which hang the lights, the heavier ones on chains. Over most tanks there is one main light (usually a $200 \mathrm{~W}$., occasionally $100 \mathrm{~W}$. bulb inside a watertight reflector fitting) 12 in. above water level and 12 in. from the top edge of each glass pane. The back lights are more numerous and more variable; they are mostly roo W. bulbs in watertight fittings, but fluorescent tubes, protected from damp, are used in places. The back lighting has been arranged to give the most effective illumination of the rock scenery and therefore varies from tank to tank; the front lighting is more constant as it is intended mainly to illuminate the animals. The triangular tanks have only one light, the front one, but special effects can be arranged if needed. Front and back lights are independently fused and switched.

In addition to the main lights, low-wattage bulbs in waterproof plastic bulkhead fittings fixed at a small number of places on the ceiling directly above the tanks (Pl. II, figs. I) are switched on whenever the main lights are off. These night-lights give sufficient illumination for a number of active fishes to avoid obstructions at night. They probably help the mackerel and some other pelagic fish and they definitely do help Smooth Hounds (Mustelus mustelus) and Spur Dogs (Squalus acanthias) to avoid bumping their snouts on rocks in the dark. The provision of night-lights was recommended long ago by Saville Kent as a result of his experiences in the former Manchester Aquarium (opened I874) and their benefit to these same species was noticed independently at Plymouth some years ago.

The floor-tank is lit partly from above by flood-lamps shining down through holes in the canopy over the tank, and partly from lamps behind plate-glass windows in the front wall below water level. The lights are so masked and positioned that they illuminate only the floor of the tank, and none of the surrounds above water level. No lamps or their reflections are visible from normal viewing positions.

At suitable points on the walls behind the tanks three-point 5-amp switch sockets are provided. These are intended for the electric cleaning pump but are available for special or temporary lighting if required.

\section{Rockwork}

Few fish are completely at ease in a bare-walled tank. Many invertebrates and some fishes need to be provided with rocky nooks and crannies and with a floor of natural sands or gravels. When an aquarium is intended to attract a paying public the appearance of this rockwork and the treatment of the tank walls is of paramount importance in providing an aesthetically pleasing background against which the animals are viewed. The success or otherwise of the scenic presentation cannot fail to influence receipts at the cash desk.

As the Plymouth aquarium is intended almost entirely for local marine life 
it was decided to base the scenic presentation on local rocks and of these the beautiful Devonian limestone forming the northern boundary of the Sound was considered most suitable. The rock is very hard and is often bluish white in colour, pink or streaked with pink. Water-worn rocks of various sizes could be picked up from higher tidal levels, and by careful attention to bedding planes could be built into natural-looking cliffs in the tanks. In addition to the use of real rocks rubber-latex moulds were made of small portions of waterworn cliff faces and used to produce artificial rock 'tiles'. One face of each tile exactly reproduces the shape and texture of the natural rock on which the mould was made. The other face, being flat and scored, forms a 'key' for cementing to the back walls, especially of the triangular tanks where it is necessary to keep the thickness of the added rockwork to a minimum. Joints between adjacent rock tiles are filled with cement and sand and modelled to merge the natural mouldings of the various tiles into one apparent solid rock face. A little of the rockwork in one triangular tank is seen in Pl. II, fig. I. A strong mix $(\mathrm{I}: 3)$ of sulphate-resisting cement and crushed limestone which had passed a $\frac{1}{4}$ in. sieve was used in making the tiles. Before filling the moulds with the mix the rubber was wetted with a strong solution of 'Teepol' to prevent the adhesion of air bubbles and, after filling, the moulds were vibrated to eliminate all air trapped in the mix. For fixing the tiles to the tank walls a stronger mix $(\mathrm{I}: 2)$ of sulphate-resisting cement, fine sands and waterproofer was used. Finally, the artificial rock faces were painted to resemble natural rocks. The epoxy resin paints used are non-toxic, are very hard and should withstand repeated cleaning. The final effect is excellent, it being difficult to distinguish artificial rocks from natural and impossible once they are covered with natural growths.

Where the back wall of a tank is left bare it is painted with epoxy resin paint of a moderately dark-green shade to simulate the effect of the greenness seen on looking through many feet of sea water. Near the backs of certain tanks frosted (sand-papered) sheets of Perspex pleasantly diffuse the background to give an appearance of distance; they eliminate shadows which would otherwise show on the walls. Scenic paintings of apparently distant rocks on the walls behind such sheets increases this illusion of remote vistas. The sheets are mostly 6 in. in front of the back wall of the tank, but sometimes are farther away and fish allowed to pass behind. They are held by slotted slates hidden in the rockwork. In arranging such sheets it is essential that side and bottom edges be concealed from view, for if seen the illusion is destroyed.

The angled-out side walls of the larger tanks are painted white (Pl. II, fig. I), again with epoxy resins. This white surface is, of course, invisible to the public and it helps to reflect back into the tank some light which would otherwise be lost. To conceal the far corners of these tanks, with their inflows and swim-ways, rock cliffs are built against the side walls a little in front of them. 
Fish can pass out of sight behind these cliffs but most fishes remain in view. Only lobsters, dogfishes, conger eels and wrasses have been troublesome, often hiding in the concealed corners, and special measures are taken to deal with them. Thus if there are more lobsters in a tank than there are hidden corners some will be forced to occupy holes in full view. Fish swimming into view from behind these cliffs and disappearing again behind them seem to come and go as they would naturally do among rocks in the sea.

After the rockwork was built the bottom of every tank was covered with a layer of sulphate-resisting cement and sand, to which a suitable yellow colouring agent had been added, and rendered to a thickness of an inch. While still wet the rendering was strewn with sand or gravel, gently patted in by hand and given a rippled surface as on a sandy sea shore. Now when fish disturb the loose sand or gravel the rippling helps to retain it in position and where patches of floors are uncovered they match well the sand or gravel and do not look like bare concrete. It is important that the bottom screeding be carried out after the rockwork is in position so that rocks emerge from it as from a natural deposit.

\section{Aquarium reservoirs and water treatments}

The provision of clean well-aerated sea water of as near normal chemical and physical constitution as possible is essential to the well-being of an aquarium. Until very recently the water supplied to the tanks of the Plymouth aquarium (from reservoirs for a description of which see Wilson, I952, p. 204) has always been loaded with varying quantities of silt, although generally satisfactory in other respects. Quite early in the history of the place much effort was expended to free the water from silt, as well as to improve it in other ways. There is frequent reference to these efforts in early Reports of Council and Director's Reports published in early volumes of the fournal. Various filters were devised which seem to have functioned for a time but which cannot have proved satisfactory for long. Conditions at one time were evidently so bad that doubts were expressed concerning the efficiency of closed sea-water circulation systems and a single use of water, at least for the laboratory, advocated (F. mar. biol. Ass. U.K., Vol. 4, pp. 77 and 4I7; Vol. 5, pp. 98-99).

The first major improvement to the condition of the circulating sea water was made when regular treatment with slaked lime (to remove carbon dioxide and restore the $\mathrm{pH}$ ) was instituted sometime after 1922 (Atkins, I93I). The silt trouble remained and occasions when it was possible to view with some clarity the backs of the largest tanks through $9 \mathrm{ft}$. of water were regarded as almost noteworthy. Most of the silt was formed in the tanks by the decay of plant growths, the breaking up of faeces, etc., and it was kept in suspension by the stirring activities of the animals, especially bottom fishes. All but the heavier components were carried away in the overflow water and discharged at the surface into one of the two underground reservoirs. From this reservoir 
water was being drawn off to the pumps at a point about $3 \mathrm{ft}$. from the bottom, and with it any silt still in suspension. There was thus a steady buildup of suspended particles and the longer the water had been circulating the cloudier it was. The cloudiness of the water in the reservoirs was such that the bottom at a depth of II $\mathrm{ft}$. was rarely visible; often it was not possible to see anything at even half that depth. Allowing each reservoir to rest and sediment alternate weeks was only partially successful in clearing the water (see below). The system has been described and criticized in Wilson, 1952, pp. 204 and 209. A method of sedimenting off the silt there suggested has now in modified form been adopted with excellent results.

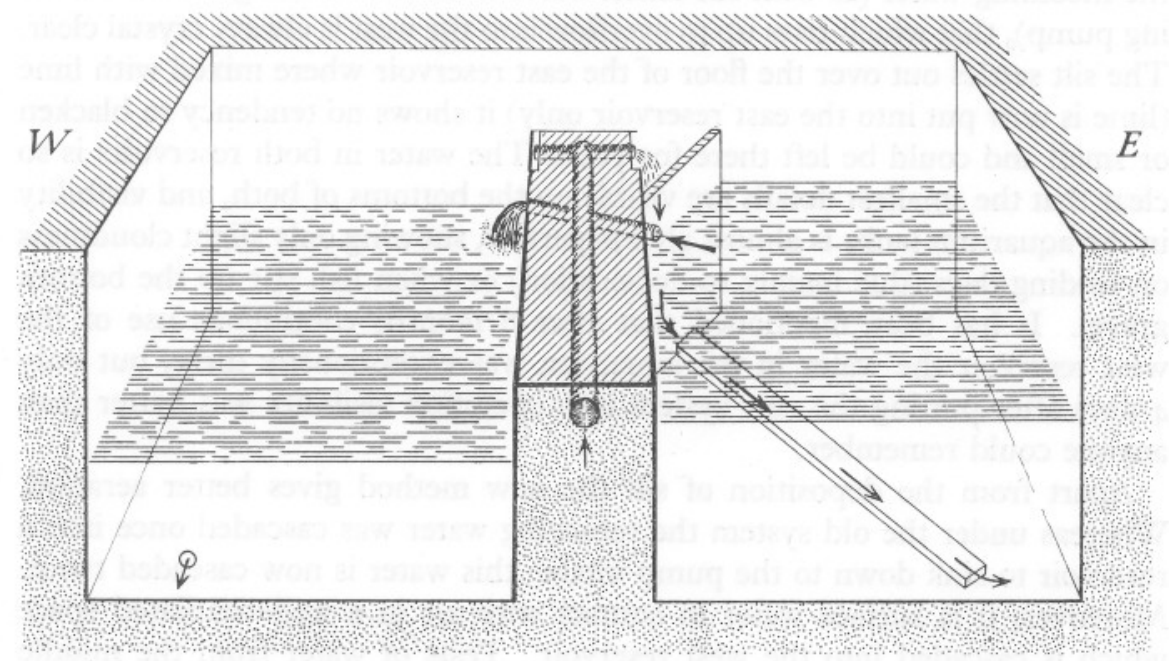

Text-fig. 6. Diagram of the sea-water reservoirs (not to scale and with roof omitted) to show method of circulation now in use. The direction of water flow is indicated by the arrows.

The method now in use involved no more than minor modifications to the existing reservoirs. These are shown diagrammatically in Text-fig. 6. Water returns from the aquarium along a $\mathrm{I} f \mathrm{ft}$. diameter pipe in the wall dividing east and west reservoirs. At its northern end there is a T-junction where sluices divert the water to one or other of the reservoirs as required; in the old days it would be the reservoir from which water was being pumped, there being then no communication between reservoirs.

During the construction of new underground reservoirs for the new laboratory circulation (see below) the east reservoir had to remain empty for 6 months and only the west reservoir was in use. During this period the water became so dirty that in the aquarium anything farther from the glass than about $2 \mathrm{ft}$. disappeared from view in a fog of suspended silt. This gives some measure of the partial success of the old method of alternating reservoirs. While the 
east reservoir was empty a wall was built across its north-west corner and from the bottom of this wall a culvert of brick sides with removable slate top was constructed across the reservoir floor to near its south-east corner. A 6 in. drain pipe was inserted through the dividing wall at the north end, passing under the larger return pipe from the aquarium. With both reservoirs flooded the return water now discharges into the corner cut off by the wall and passes along the culvert to emerge near the south-east corner at the bottom as shown by the arrows in Text-fig. 6 . This brings about a continuous overflow of surface water from the east to the west reservoir from whence it is drawn off to the pump through the old suction pipe in the south wall. However dirty the incoming water (as with silt-laden water from the discharge of the cleaning pump), that which rises up to overflow into the west is always crystal clear. The silt settles out over the floor of the east reservoir where mixed with lime (lime is now put into the east reservoir only) it shows no tendency to blacken or smell and could be left there for years. The water in both reservoirs is so clear that the smallest details are visible on the bottoms of both, and visibility in the aquarium tanks is almost always perfect, showing only slight cloudiness on feeding days (due mainly to defaecation) or when fish stir up the bottom gravel. It has been mentioned that after 6 months continuous use of the west reservoir the water in the aquarium was exceptionally dirty, but only 4 days after putting the new system into operation visibility was better than anyone could remember.

Apart from the deposition of silt the new method gives better aeration. Whereas under the old system the returning water was cascaded once into a reservoir to sink down to the pump intake, this water is now cascaded twice. Moreover, it is surface water in contact with air in a well-ventilated space which is cascaded into the west reservoir. Tests of water from the middle depths of the latter have shown close approximations to $100 \%$ oxygen saturation.

Means are provided whereby it is easy to revert to the old system of using one reservoir only. This is occasionally necessary for a day or two while one or other of the reservoirs is emptied and cleaned. The method of refilling from the sea was described in Wilson, 1952, p. 205. Sometimes the west reservoir is only partially emptied and the system freshened with new water from the sea pumped into the east reservoir.

The total quantity of sea water held by the reservoirs is about I I0,000 gallons when both are completely full, while the total quantity of water in aquarium and service tanks is roughly 17,000 gallons. At the present time the water is circulated at a rate of about 3000 gallons an hour (for description of the pumps see Wilson, I952, p. 204). This rate is barely adequate, especially in hot weather, and it is desirable to increase the rate to 4500 gallons per hour or even more. 


\section{NEW CIRCULATION}

An ever-increasing need for more live-specimen storage accommodation, and for research purposes cleaner water less heavily stocked with animal life, led to a decision to build an entirely new circulation system independent of the main aquarium and its ancillaries. Thus, commencing in October 1955 new reservoirs were excavated in the yard between south and north buildings and a new series of outside tanks were built to replace the smaller series illustrated and described in Wilson, 1952, pp. 202-3. The new system was brought into operation for the first time early in September 1957. The contractors for these new reservoirs and new outside tanks were Messrs A. N. Coles (Contractors) Ltd., Plymouth.

\section{New reservoirs}

A large hole was excavated in hard limestone to the east of the aquarium reservoirs. In this hole new reservoirs were constructed in concrete (using sulphate-resisting cement) and lined with a rendering of waterproof concrete coated with bituminous paint. They were roofed over at road level with concrete and tarmacadam. The roofing is designed to take a load of 12 tons. At convenient places manholes give access to the reservoirs below. Each reservoir holds about 16,000 gallons of sea water when full and there is a wellventilated air-space of about $2 \mathrm{ft}$. between the underside of the roof and the water surface. The dividing wall between the reservoirs has three wide openings $8 \mathrm{ft}$. 9 in. above reservoir floor level. Water returning from the tanks cascades into a partitioned-off space in the south-east corner of the east reservoir and is there forced to descend to the bottom where silt is deposited. As this east reservoir fills up it overflows the dividing wall through the openings mentioned and cascades into the west reservoir. The depth of the water as it passes over the flat top of the 12 in.-wide wall is very shallow; thus the whole volume of the water as it circulates is at these places brought into close contact with air. From a position $4 \mathrm{ft}$. above floor level at the west end of the west reservoir the water is sucked away through a black polythene pipe of 3 in. bore to the pumps. The east reservoir is limed weekly through an inspection cover. Provision is made for working from either reservoir only while the other is emptied and cleaned. Each reservoir is provided with a drain hole and plug at its south-west corner and the floor slopes downwards slightly to the drain hole. The 4 in. drain pipe passes under the floor of the new west reservoir and passes through the south end of the old east reservoir of the aquarium circulation to join the main drain. The depth of water in the new reservoirs varies between 8 and $9 \mathrm{ft}$. when full. The reservoirs are filled through a 4 -in. bore iron pipe and through valves connecting with the pumping system used for filling the aquarium reservoirs (Wilson, I952, p. 205). Compressed air can be supplied to the west reservoir should it ever be needed. 
Electric lights in watertight bulkhead fittings are fixed to the roof of each reservoir and are switched from the pump-room in the basement of the south building.

\section{New outside tanks}

Under a new roof a new series of outside tanks was used for the first time in September 1957. They comprise (Text-fig. I and Pl. II, fig. 2) three blocks of concrete tanks (painted internally with bituminous paint) and nine large (I00 gallon) and four small ( 20 gallon) asbestos tanks on raised plinths (Text-fig. I). A double tier of slate shelving, built partly against the main building and partly against a wall at right angles to it, forms a circulation unit for bowls and jars. Four of the concrete tanks are divisible by asbestos sheets sliding in grooves; a fifth is bowl-shaped to accommodate squid and cuttlefishes. The water depth of the smaller concrete tanks is roughly 19 in., while the water depth of the large central tank can be varied at will at 23,31 and 36 in. by placing rubber bungs in the lower overflow holes. All overflow pipes pass down inside the thickness of the tank walls and are fitted with plastic bowl-shaped sieves ('salad-shakers' from a local store) to prevent the ingress of large objects. These overflows discharge into a culvert below ground level which returns overflow water to the reservoirs. The culvert and the lower ends of all overflow pipes are readily accessible through a series of manholes. Inflow pipes are also within the thickness of the walls and discharge into the tanks close to the bottom.

The asbestos tanks are fitted with black polythene piping for inflows and overflows. They can easily be removed and other tanks of different sizes put in their place.

At the time of writing, all tanks east of the circulation benches are supplied from the new reservoirs, while the benches themselves and the tanks west of them are on the aquarium circulation. It is possible for the largest concrete tank and the three asbestos tanks near its western end to be supplied with water from the aquarium circulation should this ever be necessary.

Electric lights for viewing the outside tanks at night are provided under the roofing. It is intended at some future date to fit shutters which in summer will slide up out of the way under the roof, but which in winter can be pulled down to enclose the tank space and protect the system from frost.

\section{New pumps}

The new circulation is maintained by paired 'Mono' pumps with stainlesssteel impellers inside rubber stators. Driven by 3 h.p. three-phase motors each unit delivers about 3600 gallons an hour. One pump is run for several weeks while the other is serviced and rests as a stand-by. Adjustments to the gearing of the $\mathrm{V}$-belting will enable these pumps to give a greater output should this in future be needed. At present the output is more than ample as it 
is serving only the outside tanks and those on the first floor of the main laboratory (as described in Wilson, 1952, p. 203, ${ }^{1}$ and illustrated in Russell, I948, pl. XIX).

\section{Circulation efficiency}

The total capacity of the outside tanks and those on the first floor is about 2600 gallons; this being less than a twelfth of the reservoir capacity, a much smaller proportion of tank volume to reservoir volume than in the aquarium circulation. The relative rate of flow of the water is also much greater. Even when eventually more experimental tanks in the new block of buildings now being planned are added the new circulation will contain less animal life per unit volume than the aquarium circulation, and be relatively more efficient in every way except temperature stability. There is no regular means of heating or cooling either circulation, and while temperature changes are slow the new circulation is more affected by the weather than is the old. This is because the total volume of water is less than in the aquarium circulation and a greater proportion of it is exposed to air temperature and wind in the yard. When shutters are fitted to close in the outside tanks in winter it will be possible to reduce the rate of loss of heat, though it is doubtful if shutters will help to check rise of water temperature during hot days in summer.

My thanks are due to Mr G. A. W. Battin for making the drawings for this paper and Mr A. C. G. Best for help with the photography.

\section{REFERENCES}

Allen, E. J. \& Harvey, H. W., I928. The Laboratory of the Marine Biological Association at Plymouth. F. mar. biol. Ass. U.K., Vol. 15, 735-51.

AtkINS, W. R. G., I93I. Note on the condition of the water in a marine aquarium. F. mar. biol. Ass. U.K., Vol. 17, pp. 479-8r.

GARNAUD, J., I952. Structure nouvelle de l'aquarium moderne et autres améliorations techniques. Bull. Inst. océanogr. Monaco, No. I,oI I, pp. I-IO.

Russell, F. S., I948. The Plymouth Laboratory of the Marine Biological Association of the United Kingdom. F. mar. biol. Ass. U.K., Vol. 27, pp. 76I-74.

WILSON, D. P., 1952. The aquarium and sea-water circulation system at the Plymouth Laboratory. F. mar. biol. Ass. U.K., Vol. 31, pp. 193-212.

— 1953. Notes from the Plymouth aquarium. II. F. mar. biol. Ass. U.K., Vol. 32, pp. $199-208$.

${ }^{1}$ Except that the overflow water from these main laboratory tanks no longer runs into exhibition tanks in the aquarium below but is conducted by new piping to the return culvert to the new reservoirs. 


\section{EXPLANATION OF PLATES}

\section{Plate I}

General view of the new aquarium from the public entrance lobby. Note the handrail, label frames, ceiling with inset lights, etc. (A photograph of the old aquarium from almost the same viewpoint is reproduced in Russell, I948, pl. XXIII, fig. I.)

\section{Plate II}

Fig. I. View along the tops of the tanks of the south side from the west end. Note especially the shapes of the tanks, the lintel walk-way and cat-walks, the overhead conveyor track, details of inflows and overflows so far as visible, sea-water and compressed-air pipes (one of the latter on tank-back near right foreground), light fittings, etc. Compare especially with Textfigs. 4 and 5 .

Fig. 2. View of new outside circulation tanks and circulation bench from the western end. Note in right foreground a pair of concrete tanks painted internally with black bitumen. Further on is the double-tiered circulation bench for bowls, and, in front, four small asbestos tanks on a low circulation table. Behind the circulation bench the outer of three large asbestos tanks, on a raised plinth, is seen. Farther on still is the large and deep concrete tank, then a pair of shallower concrete tanks similar to those in the foreground. Beyond these part of a row of three large asbestos tanks is just visible. (For photographs of the old outside circulation which these tanks replace see Russell, 1948, pl. XXII, fig. 2, and Wilson, 1952, text-fig. 4). 


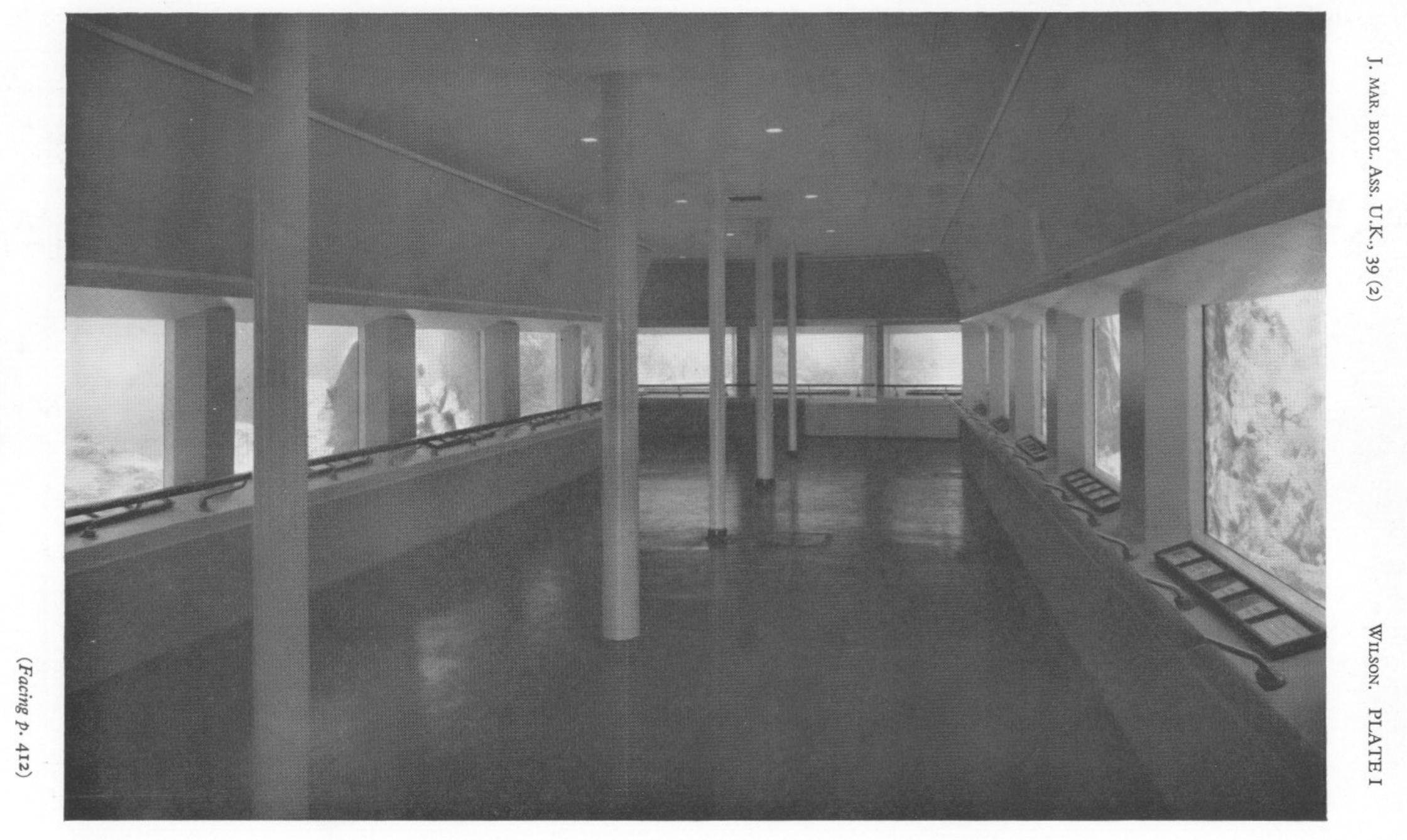




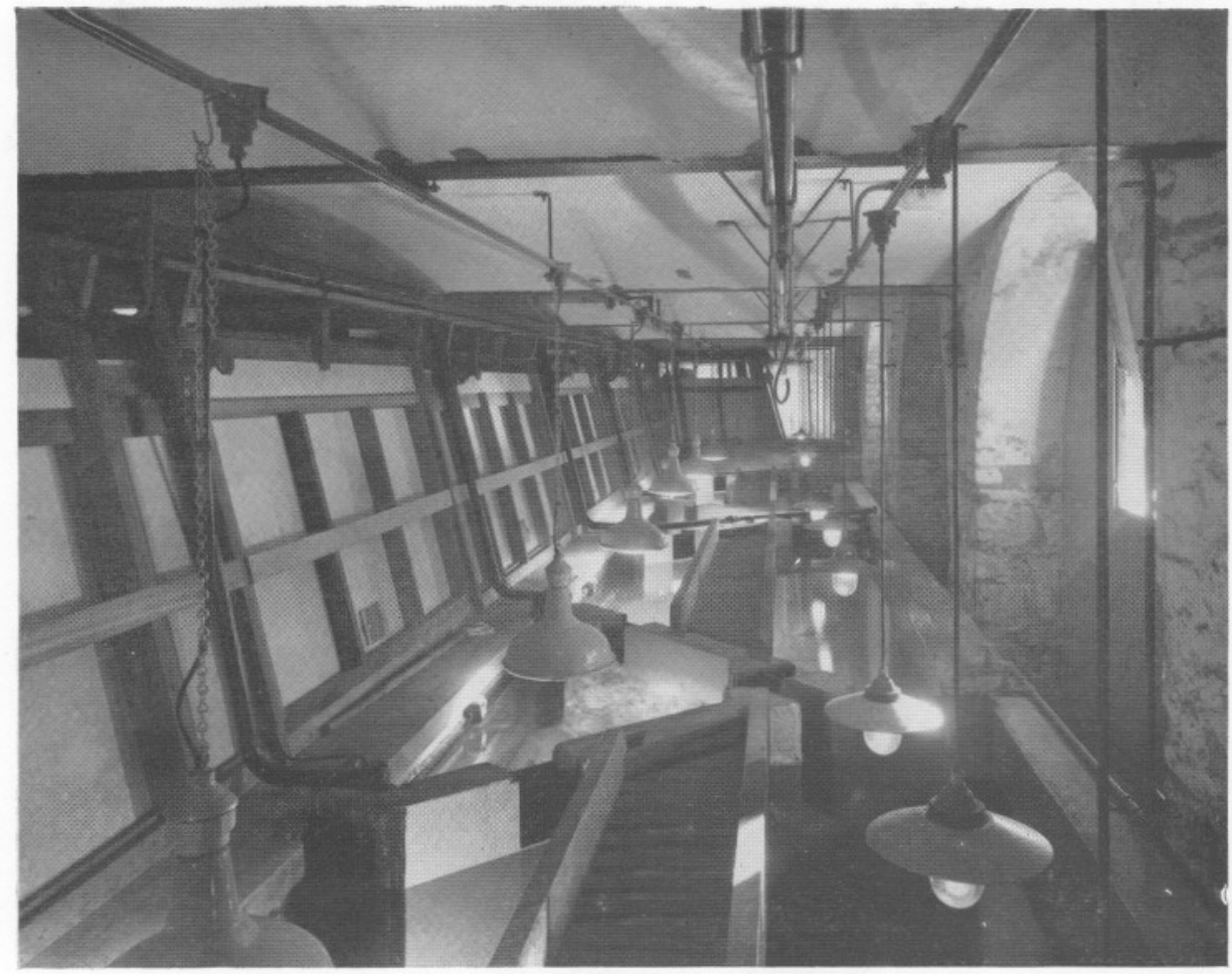

Fig. I.

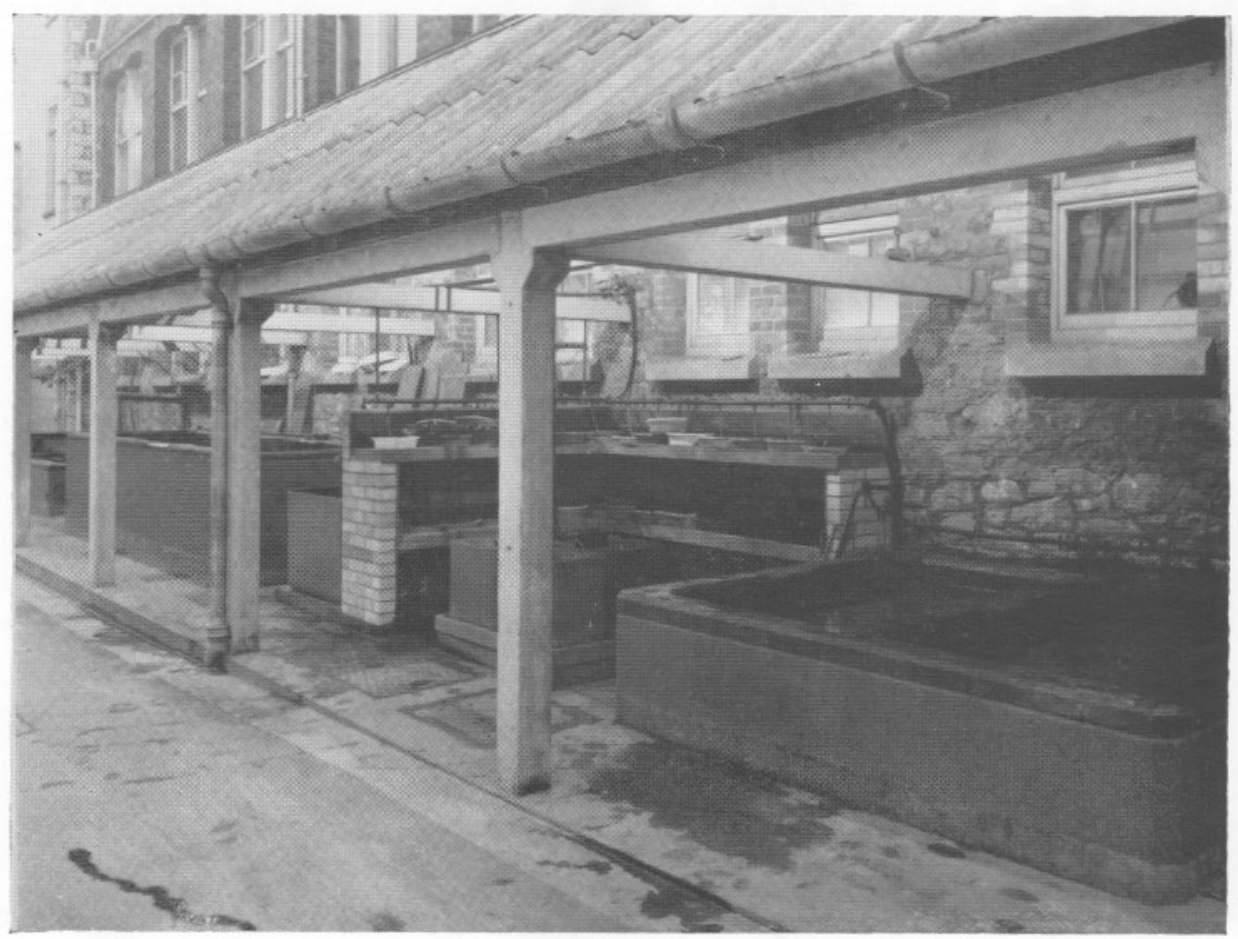

Fig. 2 . 